\title{
PENYUSUNAN PIRANTI LUNAK TIPOLOGI PENELITIAN SUMBER DAYA AIR
}

\author{
Yeni Nuraeni ${ }^{1}$ \\ e-mail :yeninur@hotmail.com
}

Diterima :17 Februari 2011/Disetujui : 3 Maret 2011

\begin{abstract}
Currently in Indonesia, the problem of water resources is no longer a problem easy to solve. Determination kebutuhanpun not easy because perubahannyapun very dynamic, as well as changes in land status is also changing rapidly. But in general there are two types of areas that lack water and in areas of excess water. Therefore it is necessary to change thinking patterns that had been considered the water is a substance that is easy to get into a substance that is rare and as a commodity that is necessary for the construction and development of the nation Indonesia.Permasalahan that arise in the handling of clean water in the transmigration settlement during this adoption of uniform policy for all packages of natural conditions, is the number of clean water facilities are not functioning. This is because water resources research methodologies that are used less attention to its natural condition. Given the need for water resources are increasingly demanding a more rapid identification process by considering the multi-parameter hydrology. Speed of identification is dependent on the available information and analysis sharpness information. Meanwhile, computerized and decision-making process is an effective tool in order to accelerate the assessment of potential water resources to the preparation of software typology air.Perapan Software resources, is one form that can be used in the context of computerized decision-making in order to realize the identification of the source the water quickly and thoroughlyg Given the Software using the rules of research ideally, it would require the input and output field observations and an accurate literature review
\end{abstract}

Keywords: Typology of Water Resources Research

1. Dosen Program Studi Teknik Informatika Universitas Paramadina - Jakarta

J1. jend Gatot Subroto Kav.96-97, Jakarta Selatan 12700, Jakarta 


\section{ABSTRAKSI}

Saat ini di Indonesia, masalah sumber daya air tidak lagi menjadi masalah yang mudah untuk dipecahkan. Penentuan kebutuhanpun tidak mudah karena perubahannyapun sangat dinamik, demikian pula perubahan status lahan juga berubah dengan pesat. Namun secara umum ada dua jenis kawasan-kawasan yang kekurangan air dan kawasan yang kelebihan air. Oleh karena itu perlu mengubah pola berpikir yang tadinya menganggap air merupakan suatu zat yang mudah didapat menjadi suatu zat yang langka dan sebagai salah satu komoditi yang sangat diperlukan bagi pembangunan dan pengembangan bangsa Indonesia.Permasalahan yang timbul dalam penanganan air bersih di pemukiman transmigrasi selama ini dengan diterapkannya kebijakan penyeragaman paket-paket untuk semua kondisi alam, adalah banyaknya fasilitas air bersih yang tidak berfungsi. Hal ini karena metodelogi riset sumber daya air yang digunakan kurang memperhatikan kondisi alamnya. Mengingat kebutuhan akan sumber daya air yang semakin meningkat menuntut proses identifikasi yang lebih cepat dengan mempertimbangkan multi parameter hidrologi. Kecepatan identifikasi ini tergantung kepada informasi yang tersedia dan ketajaman analisa informasi tersebut. Sementara itu, komputerisasi dan proses pengambilan keputusan merupakan alat yang efektif dalam rangka mempercepat penilaian potensi sumber daya air dengan penyusunan piranti lunak tipologi sumber daya air.Perapan Piranti Lunak ini, adalah salah satu bentuk yang dapat dipergunakan dalam rangka komputerisasi pengambilan keputusan guna terwujudnya identifikasi sumber daya air secara cepat dan teliti. -Mengingat Piranti Lunak menggunakan kaidah-kaidah penelitian secara ideal, maka diperlukan masukan dan hasil observasi lapangan dan kajian pustaka yang akurat

Kata Kunci: Tipologi Penelitian Sumber Daya Air

\section{PENDAHULUAN}

Setelah dilakukannya berbagai kebijakan pembangunan fisik dan telah pula diketahui berbagai kendala akan masalah sumber daya air, maka perlu pemikiran untuk melakukan penyesuaian kebijakan-kebijakan sesuai dengan tuntutan pembangunan.

Suatu kegiatan pengembangan wilayah dalam arti yang luas, di dalam perencanaannya terdapat tiga komponen utama: manusia, alam, dan aktivitas manusia. Manusia sangat memerlukan air untuk hidup dan mengembangkan aktvitasnya. Sementara itu, sudah terbukti bahwa ketersediaan sumber daya air potensial tidak beragam keberadaannya. Oleh karena itu, sudah menjadi keharusan menempatkan air sebagai parameter kontrol/kendala pada saat melakukan peniaian kelayakan suatu lahan transmigrasi, demikian pula pada saat menentukan rincian peruntukan suatu lahan.

Lima pertanyaan dasar dalam mengevaluasi potensial sumber daya air suatu wilayah: 
a. Adakah sumber daya air potensial

b. Dimana dan bagaimana terdapatnya potensi tersebut

c. Bagaimana perilaku ketersediaan (kuantitas dan kualitas) potensi tersebut sebagai fungsi dari waktu

d. Teknik konservasi yang bagaimana yang perlu dilakukan

e. Bagaimana cara mengambilnya, menentukan kombinasi pemanfaatan potensi air (apabila terdapat lebih dari satu jenis sumber air) dalam kaitannya dengan penataan ruang.

Melihat tidak mudahnya menjawab kelima pertanyaan tersebut, maka sangat mudah dipahami bahwa untuk penanganan masalah ini perlu penanganan secara terpadu, artinya perlu investasi awal yang besar untuk mengkaji berbagai data yang telah ada saat ini yang tersebar diberbagai sumber data/institusi di Indonesia.

Masalah investasi yang dimaksud tidak hanya menyangkut pendanaan, tetapi lebih dari itu, yaitu perlunya keterbukaan lintas sektoral dan meningkatkan saling pengertian akan keahlian para peneliti agar suatu laporan penelitian menjadi lebih tajam penalarannya.

Hal ini perlu dilakukan untuk membantu agar para pengambil kebijakan dalam masalah air di Indonesia menjadi lebih cepat dan lebih berorientasi kepada hal-hal yang lebih realistis.

\section{KONSEP-KONSEP UTAMA}

\section{Proses Pengambilan Keputusan Dalam Permasalahan Sumber Daya Air}

Setelah mencoba mempelajari situasi saat ini di Indonesia baik melalui kajian kepustakaan maupun dari hasil-hasil seminar, maka ada beberapa kelompok pekerjaan besar yang masih belum tertangani dalam kaitannya dengan masalah sumber daya air di Indonesia:

1. Merumuskan dan menstrukturkan berbagai macam data hidrologi (air meteorik, air permukaan, dan airtanah) yang berada (tersebar) di berbagai institusi (Pemerintah dan Swasta);

2. Merumuskan kriteria kebutuhan air (domestik/non domestik);

3. Melanjutkan penelitian-penelitian potensi sumber daya air yang diikuti dengan melakukan karakterisasi perilaku sumber daya air yang ada dan mengarah kepada penelitian sumber daya air potensial

4. Melakukan evaluasi daya dukung sumber daya air potensial (kuantitas dan kualitas) sebagai parameter kontrol sekaligus sebagai parameter kendali untuk 
penentuan strategi pengembangan wilayah, baik dalam kaitannya dengan Rencana Umum Tata Ruang Daerah (RUTRD), Propinsi bahkan Tata Ruang Nasional.

Selanjutnya, untuk memberikan nilai tambah dalam arti perencanaan pengembangan suatu wilayah secara umum maka perlu mempertimbangkan hal-hal dibawah ini:

1. Bank Data sumber daya air

2. Peta Keperluan dan Peta Sumber Daya Air Potensial

3. Peta Zoning Potensi Bencana Air dan Strategi Mitigasinya

4.Evaluasi lokal terhadap Rencana Umum Tata Ruang, khusus permasalahan sumber daya air

5. Menyusun kriteria dan standar Teknologi konservasi air dan tanah

6.Aspek hukum dan sosial untuk kelestarian pemanfataan sumber daya air.

Air, yang merupakan salah satu parameter dalam penyusunan dan pengembangan wilayah perlu dijadikan parameter kendali dalam penyusunan tata ruang dan suatu rencana kawasan Transmigrasi. .

\section{Konsep Aplikasi Komputer Dalam Tipologi Sumber Daya Air}

Pada dasarnya sumber daya air terdiri dan tiga bagian utama yaitu; Air Hujan, Air tanah,Air Permukaan. Suatu perencanaan wilayah sebaiknya mempertimbangkan potensi dari masing-masing sumber daya air di atas. Potensi sumber daya air ini dapat ditentukan dengan memanfaatkan parameter-parameter pendukung, seperti ; Curah hujan, kelembaban udara, dsb.

Dalam perencanaan pemanfaatan sumber air untuk menentukan jenis sarana air berrsih yang sesuai dan akan diterapkan di suatu lokasi transmigrasi diperlukan beberapa kriteria sebagai acuan. Kriteria yang paling mendasar adalah menyangkut persyaratan baku jumlah dan baku mutu air bersih yang harus dipenuhi bagi suatu sistem penyediaan air berrsih. Dengan demikian diharapkan agar air dapat tersedia dalam jumlah yang cukup dengan mutu yang memenuhi syarat-syarat mutu air dan dapat dimanfaatkan oleh para transmigran dengan aman, baik untuk keperluan air minum maupun keperluan lainnya dalam jumlah yang memadai.

Sehubungan dengan banyaknya parameter dan data pendukung, maka proses penentuan potensi sumber daya air secara manual dirasakan kurang efektif. Hal ini disebabkan oleh karena proses manual akan menyebabkan lambatnya pengambilan keputusan. 
Untuk itu peranan komputer sebagai alat pengambilan keputusan mulai diperlukan. Dengan bantuan komputer, maka proses pengambilan keputusan dapat dipercepat. Pada pelaksanaanya, hal di atas memerlukan beberapa persyaratan:

- Kejelasan data informasi yang diperlukan

- Kejelasan mekanisme pengambilan keputusan

- Kejelasan jenis-jenis keputusan yang diinginkan.

Dengan kombinasi antara berbagai macam data/informasi dan mekanisme pengolahan data, maka dapat diperoleh berbagai macam keputusan. Berdasarkan pemikiran di atas, maka diperlukan adanya matriks keputusan yang menggambarkan pilihan-pilihan yang dapat diambil sebagal dasar penentuan lokasi pemukiman. Dalam hal ini, faktor data base dari sumber daya air merupakan bagian yang tidak dapat diabaikan. Sesuai dengan tipologinya, maka data base disini dapat digolongkan atas data base air hujan, airtanah dan air permukaan. Masing-masing jenis data base tersebut kemudian diolah berdasarkan mekanisme maupun rumus-rumus yang ada.

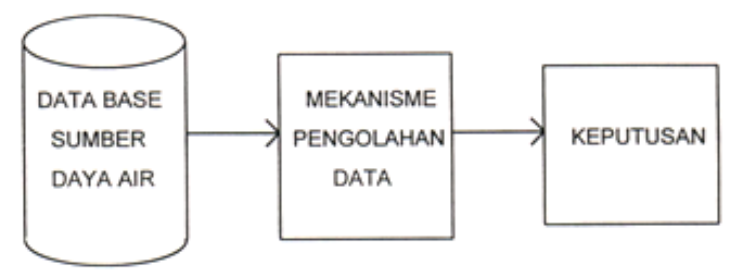

Keputusan diambil sebagai hasil pertimbangan dan potensi-potensi sumber daya air yang telah dihitung dengan memakai mekanisme yang berkaitan. Dengan demikian data hasil penelitian lapangan secara cepat dapat diolah untuk dapat mengetahui apakah daerah tersebut memiliki sumber daya air yang berpotensi tinggi.

\section{METODOLOGI}

Perancangan pemenuhan kèbutuhan air disuatu wilayah transmigrasi yang akan dibuat hendaknya betujuan untuk efisiensi pemanfaatan air dan pemahaman masalah konservasi air tanah, yang dituangkan dengan standar-standar pengembangan. Departemen Tenaga Kerja dan Transmtgrasi dalam upaya penanganan air bersih selama ini telah menerapkan paket penanganan yang seragam untuk seluruh kawasan transmigrasi. Paket-paket tersebut umumnya :

a. Untuk pemafaatan air hujan yang jatuh di atap penduduk maka dibuat Bak Penampungan Air Hujan (BPAH)

b. Untuk pamanfaatan air yang mengalir di sungai-sungai kecil/alur maka dibuat Tandon/Bendali 
c. Untuk pemanfaatan air tanah maka dibuat sumur dangkal $(<10 \mathrm{~m})$ atau pemboran alr tanah dalam (sumur dalam)

Dari data yang dikumpulkan oleh Pusat Pengolahan Data,Departemen Tenaga Kerja dan Transmigrasi mengenai keadaan fasilkas air bersih di berbagai lokasi transmigrasi kebijakan penyeragaman paket-paket tersebut diatas perlu segera dievaluasi mengingat banyak fasilitas-fasilitas di atas yang tidak bertungsi sebagaimana mestinya. Permasalahan yang timbul antara lain tañdon air yang tidak berfungsi, sumur gali yang kering,banjir,dan lain-lain. Hal-hal di atas membawa kata kepada suatu pemikiran perlunya dirumuskan upaya-upaya penanganannya.

Untuk penanganan masalah ini perlu diambil langkah-langkah secara terpadu, antara lain dengan mengangkat masalah sumber daya air menjadi kendala atau parameter kendala dalam penilaian kelayakan suatu lahan untuk penerapan model-model transmigrasi dimana konsukuensinya diperlukan penyempumaan metodologi dan sistem penanganan masalah air secara terpadu dan lebih terstruklur dengan mengacu kepada kebutuhan air dimasa yang akan datang.

Berangkat dari kebutuhan ini, Departemen Tenaga Kerja dan Transmigrasi perlu merumuskan metodologi dan sistem penanganan masalah air melalui penyusunan dokumen Tipologi Paket Penelitian Sumber Daya Air Menunjang Perencanaan Pemukiman Transmigrasi.

Dokumen Tipologi ini akan memberikan arahan dan tuntunan kepada konsultan untuk melakukan penetitian terhadap sumber daya air yang ada di dalam atau di luar wilayah yang akan dikembangkan.

BAGAN POSISI TIPOLOGI DALAM KONTEKS PERENCANAAN TRANSMIGRASI

PHASE PERENCANAAN TRANSMIGRASI
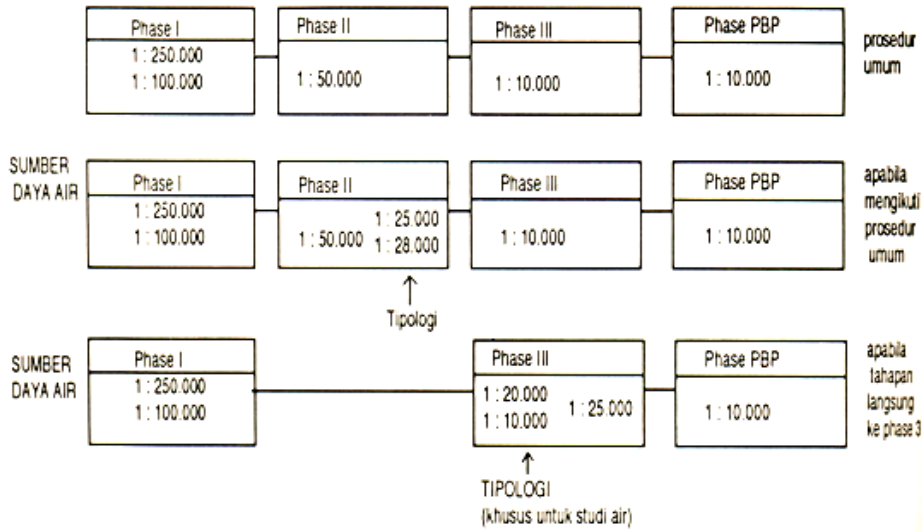
ALUR PENELITIAN SUMBER DAYA AIR PHASE II (MENURUT TIPOLOGI SDA)

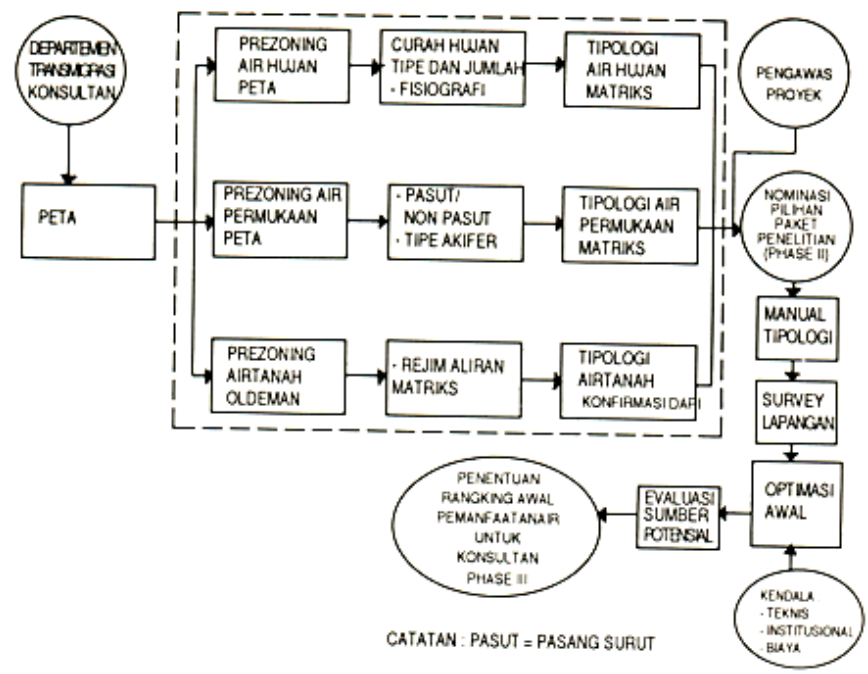

PERBEDAAN KONSEPTUAL (ASPEK SUMBER DAYA AIR)

\begin{tabular}{|l|l|}
\hline \multicolumn{1}{|c|}{ PRA. TIPOLOGI } & \multicolumn{1}{|c|}{ MENURUT TIPOLOGI } \\
\hline Tumbuhan ada maka manusia hidup & $\begin{array}{l}\text { Kebutuhan air untuk tumbuhan dan } \\
\text { manusia harus sama-sama diperhatikan } \\
\text { secara rinci }\end{array}$ \\
\hline $\begin{array}{l}\text { Perhatian utama air untuk ke } \\
\text { perluan Pertanian }\end{array}$ & $\begin{array}{l}\text { Perhatian air untuk pertanian dan } \\
\text { kebutuhan manusia }\end{array}$ \\
\hline $\begin{array}{l}\text { Belum menerapkan konsep DAS } \\
\text { dan cekungan air tanah }\end{array}$ & $\begin{array}{l}\text { Konsep DAS dan cekungan airtanah } \\
\text { sebagai acuan pengelolaan sumber } \\
\text { daya air }\end{array}$ \\
\hline $\begin{array}{l}\text { Peneltian air antar Phase tidak } \\
\text { Konvergen }\end{array}$ & $\begin{array}{l}\text { Penelfian air dari Phase I ke Phase III } \\
\text { bersitat Konvergen }\end{array}$ \\
\hline $\begin{array}{l}\text { Air belum dijadikan salah satu } \\
\text { parameter kendali dalam pe. } \\
\text { nyusunan tata ruang }\end{array}$ & $\begin{array}{l}\text { Air merupakan salah satu parameter } \\
\text { kendali dalam penyusunan tata ruang }\end{array}$ \\
\hline $\begin{array}{l}\text { Metoda dan analisa eksplorasi air } \\
\text { belum memperhatikan kondisi } \\
\text { alam }\end{array}$ & $\begin{array}{l}\text { Metoda dan analisa eksplorasi ini } \\
\text { sudah dirumuskan dalam matriks } \\
\text { Tipologi dan Paket penelitiannya }\end{array}$ \\
\hline $\begin{array}{l}\text { Menghasitkan peta Hidrologi yang } \\
\text { hanya memuat intormasi lokasi } \\
\text { pengamatan dan pengambilan } \\
\text { contoh air (Phase IIIMenghasilkan }\end{array}$ & $\begin{array}{l}\text { RTPAB (Rencana Teknis Penanganan } \\
\text { Air Bersih) dibuat paralel dengan } \\
\text { RTSP dan RT J (Phase III) } \\
\text { LAPI-ITB (1993) }\end{array}$ \\
\hline
\end{tabular}




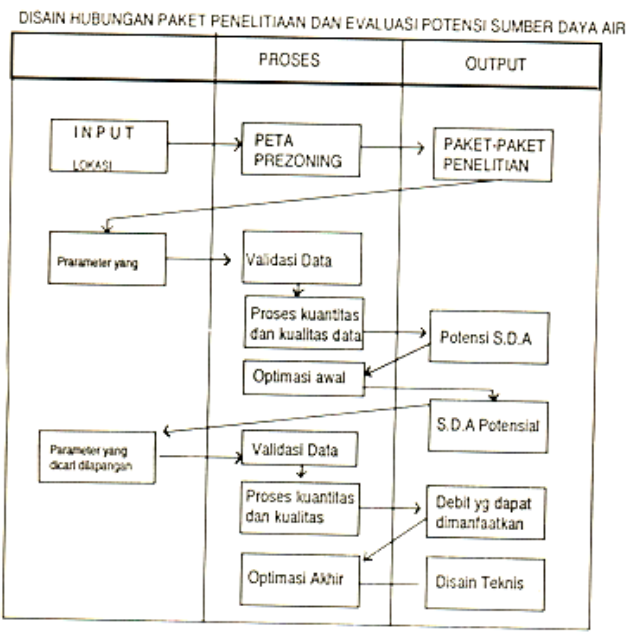

\section{HASIL DAN PEMBAHASAN}

Untuk mempercepat proses penyaringan (mengingat banyaknya parameter tipologi) dan efektifitas penerapannya maka dirasa perlu agar paket Tipologi Sumber Daya Air ini dikembangkan melalui pembuatan Sistem Pakar (Expert System) yang diawali dengan pembuatan Sistem Informasi Manajemen Sumber Daya Air (SIM SDA) dan Sistem Pengambilan Keputusan Sumber Daya Air (SPK SDA) atau Decision Support System (DSS).

Penerapan Piranti Lunak menggunakan kaidah-kaidah penelitian secara ideal, maka diperlukan masukan dari hasil observasi lapangan dan kajian pustaka yang akurat. Peran konsultan akan sangat dominan pada tahapan observasi dan pengumpulan data (lapangan dan pustaka). Peran konsultan dituntut sangat akurat dalam kemahiran menalar/ menganalisa kondisi lapangan pada kasus dárurat yaitu apabila tahapan phase II tidak dilakukan.

\section{Tujuan Piranti Lunak yang perlu dibuat:}

1.Merumuskan Tipologi Manual kedalam rancangan Sistem Tipologi yang siap dituangkan dalam bentuk Piranti Lunak.

2.Menciptakan suatu Sistem Pengkajian dan Péngolahan Informasi Sumber Daya Air dengan bantuan komputer,khususnya dengan mengaplikasikan Piranti Lunak dengan GIS.

Dengan bantuan Piranti Lunak SDA, ketajaman analisis Sumber Daya Air diharapkan dapat lebih terjamin. Dengan demikian, diharapkan dapat memberikan 
hasil analisis secara cepat dan mendekati kesempurnaaan sehingga penataan ruang akan lebih tepat.

Piranti lunak Tipologi Sumber Daya Air (TIPSDA) terbagi atas dua subsistem:

- $\quad$ Subsistem GIS (Geographic Infomation Sistem) dalam hal ini digunakan piranti lunak GIS “ARC/INFO”.

- $\quad$ Subsistem DSS (Decision Suppod Sistem) yang dibangun dengan menggunakan bahasa Pascal dengan teknik perancangan "Orientasi Object".

Paduan dua subsistem ini menjadikan sistem Informasi geografis lebih supel dan informative, Basis data yang diolah melalui subsistem DSS setiap saat dapat dibaca melalui GIS. Dengan menu pop-up serta aplikasi multi-jendela pada DSS, lnformasi yang diperlukan dapat ditampilkan secara simultan dengan cukup menggerakan MOUSE. Tampilan keterangan bantu pada layar bagian bawah akan menuntun pemakai lebih interaktif dengan program.

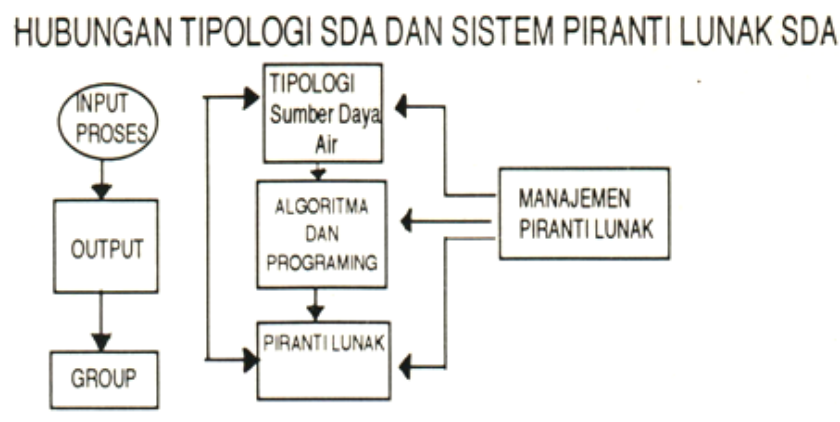

SISTEM PERANCANGAN PIRANTI LUNAK TIPOLOGI PENELITIAN SDA

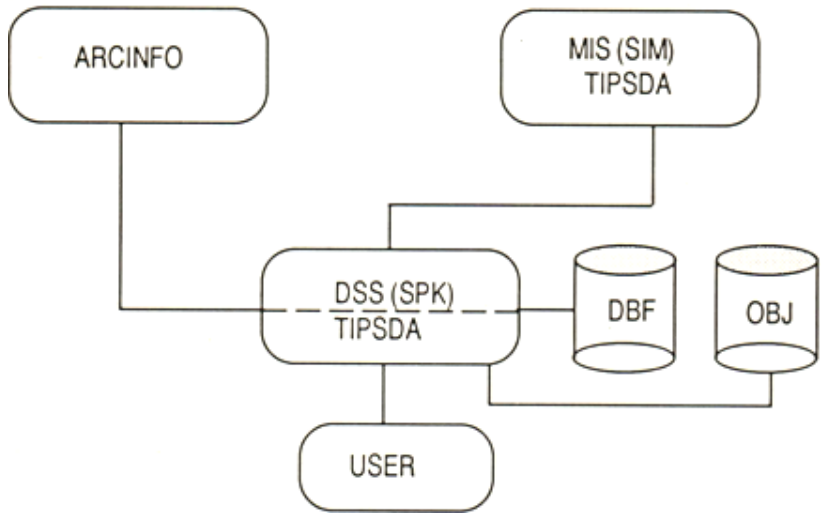



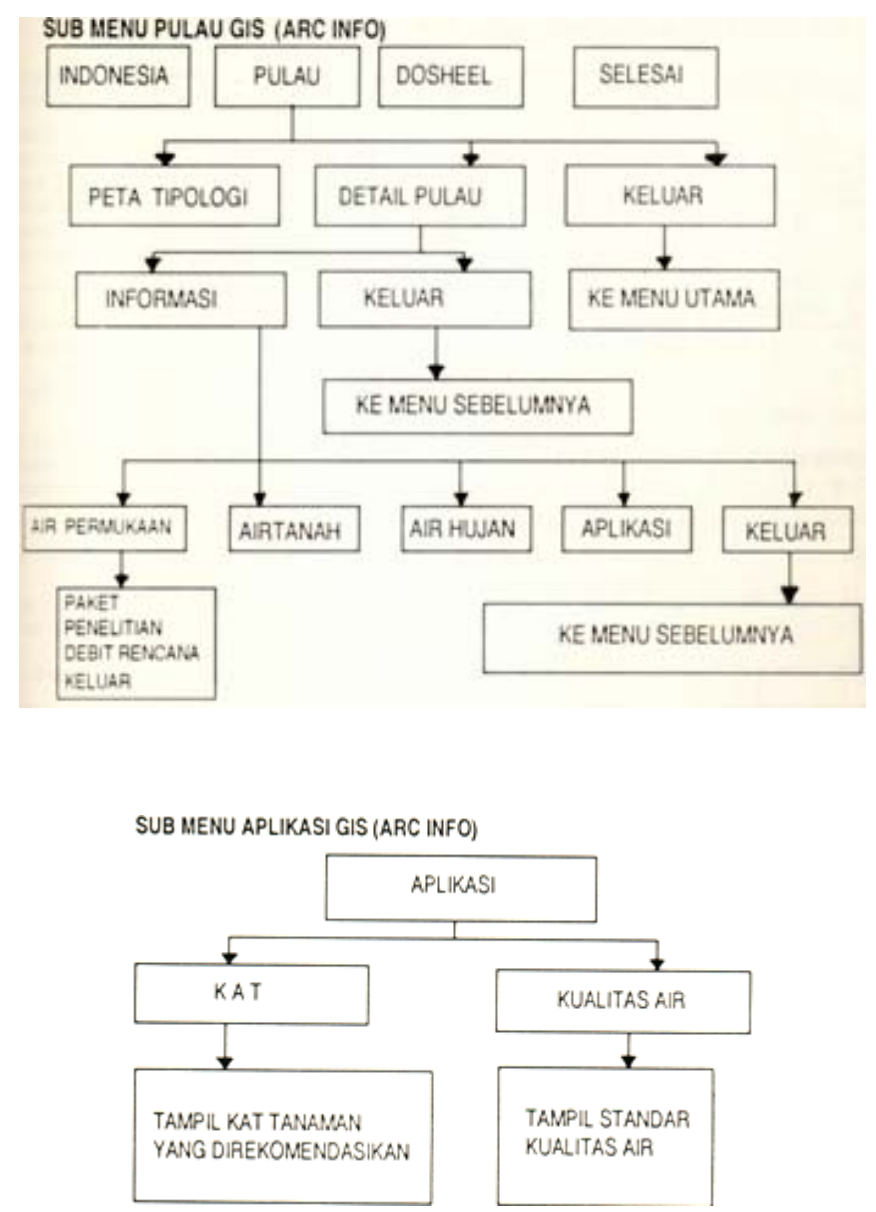

Peranti lunak Sistem Pengambil Keputusan (SPK) Tipologi SDA dibuat berdasarkan masukan ARC/INFO dan MIS. Piranti Lunak ini menggunakan dan juga menghasilkan data base dalam format DBF. Teknik pemrograman MIS Tipologi SDA berorientasi objek.

Perlu ditekankan pada bagian ini, bahwa komputerisasi sistem pendukung pengambilan keputusan Sumber Daya Air ini bukan satu-satunya konsep dalam perencanaan tata ruang. Lebih dari itu, Piranti Lunak Sumber Daya Air ini perlu didukung oleh sistem pengambilan keputusan yang didasarkan pada aspek-aspek lainnya, seperti: masalah bentang alam, tanah, tumbuhan penutup, konsep-konsep tentang bencana alam dan sebagainya. Untuk itu, keterpaduan informasi air dengan aspek-aspek tersebut di atas akan menjadi dasar yang kokoh dalam sistem pendukung pengambilan keputusan ( DSS ) perencanaan tata ruang pemukiman. Dengan 
demikian, sebagai pengembangan selanjutnya, sistem pendukung keputusan ini seharusnya dilengkapi dengan ; DSS Bentang AIam, DSS Tanah, DSS Tumbuhan Penutup, DSS Bencana Alam, DSS Informasi Bisnis dll. .

Berdasarkan pemikiran di atas, maka sistem perencanaan transmigrasi bisa dikembangkan lebih jauh kearah komputerisasi dan aspek-aspek yang disebut terakhir tadi. Pada dasarnya, pengembangan setiap DSS ini dapat ditangani seluruhnya oleh Departemen Tenaga Kerja dan Transmigrasi dan atau oleh institusi lain. Satu hal yang sangat diperlukan adalah DSS yang dikembangkan di suatu instansi harus memiliki sistem interaksi dengan DSS lainnya yang mungkin berada di instansi lain lagi. Sebagai salah satu alternatif dari keterpaduan antar DSS ini adalah pengembangan sistem pakar perencanaan transmigrasi yang di dasarkan pada system multi-

\section{kriteria.}

\section{MODEL PENYUSUNAN SISTEM PAKAR}

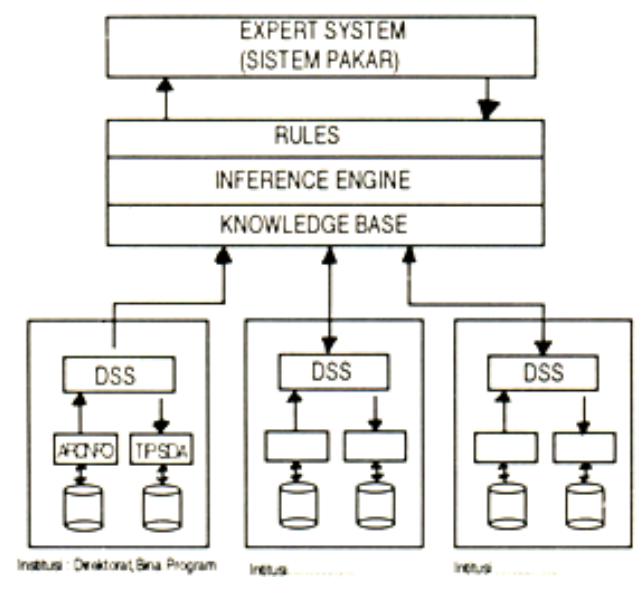

Penyusunan Peranti Lunak Tipologi Sumber Daya Air mempunyai tujuan akhir adalah penyusunan Sistem Pakar untuk perencanaan pemukiman transmigrasi secara utuh dengan memperhatikan berbagai parameter lain. Untuk merealisasikan Sistem Pakar di atas masih diperlukan berbagai upaya dalam menyusun DSS lainnya: DSS Bentang Alam, DSS Tanah, DSS Vegetasi, DSS Bencana Alam dan lain-lain yang mampu memberi masukan yang berarti bagi perencana pemukiman .

Sistem pakar dibangun melalui beberapa tahapan yaitu :

1. Tahap pembangunan Sistem Informasi Manajemen (Management Information System Development) 
Pembangunan SIM ini merupakan proses komputerisasi informasi untuk kepentingan manajemen masing-masing departemen.

2. Tahap pembangunan Sistem Pendukung keputusan(Desicion Support System Development)

Pembangunan DSS ini merupakan aplikasi SIM terpadu yang didukung oleh metoda dan prosedur, sehingga keputusan akurat dan alternatif dapat diperoleh dengan cepat. DSS dapat dilakukan intra departemen atau antar departemen

3. Tahap pembangunan Sistem Pakar (Expert System Development)

Informasi dari DSS antar departemen dipadukan menjadi satu kesatuan dalam mewujudkan kepentingan bersama (nasional) melalui satu proses pengolahan tersebar-terpadu (integrated distributed processing)

\section{KESIMPULAN}

Dalam rangka komputerisasi masalah SDA diperlukan adanya kejelasan dan definisi kebutuhan akan air. Wawasan dan informasi dari para pakar masalah air merupakan faktor yang dominan dalam pembuatan piranti lunak SDA.

Pengolahan Bata Base air dalam scope nasional memertukan adanya: Standar dan struktur data informasi. Sistem pangkalan data SDA adalah salah satu alternatif dalam rangka integrasi informasi tentang air.

Hubungan lintas sektoral merupakan dukungan yang besar dalam perencanaan tata ruang transmigrasi (dalam hal ini kriteria perencanaan tata ruang dapat ditinjau dari banyak aspek, seperti air, bentang alam, bencana alam, tanaman penutup, tanah, informasi, bisnis, dan lain-lain). Diperlukan adanya integrasi (komunikasi) antar instansi terkait dalam hal ini, integrasi lewat piranti lunak adalah salah satu solusinya

Kedudukan piranti lunak sumber daya air merupakan dasar dari prinsip system pendukung pengambilan keputusan dalam perencanaan transmigrasi. Sebagai langkah pengembangan, maka peranan system pakar menjadi cukup penting dalam rangka keterpaduan criteria perencanaan pemukiman.

\section{PUSTAKA}

1. Anonymous, 2000, Understanding G.I.S. The ACRC/Info Method.

2. Burrough P.A., 2004. Principles of Geographical Information Systems for Land Resources Assessment.

3. Rosadi D., Sukrisno and Wagner W., 2000, Groundwater resources and Groundwater Protection in the Bandung Basin Proyect Report No. 15, Directorate of Environmental Geology Bandung. 
4. Turban,E., Dicision Support and Expert Sysstem : Management Support System, New York

5. Jayaraman, V. and Srivastava, R.(1996), "Expert systems in production and operations management", International Journal of Operation \& Production Management, Vol 16 no. 12,pp. 27-44

6. LAPI-ITB, Departemen Transmigrasi,Penyusunan Tipologi Penelitian Sumber Daya air Menunjang Perencanaan Pemukiman Transmigrasi, 1994 